\section{$\underset{\substack{\text { hommes } \\ \text { \& migrations }}}{ }$}

\section{Hommes \& migrations}

Revue française de référence sur les dynamiques

migratoires

$1311 \mid 2015$

Femmes et migrations

\title{
Elles... leur combat pour la visibilité
}

\section{Marie Poinsot}

\section{(2) OpenEdition \\ Journals}

\section{Édition électronique}

URL : http://journals.openedition.org/hommesmigrations/3232

DOI : 10.4000/hommesmigrations.3232

ISSN : 2262-3353

\section{Éditeur}

Musée national de l'histoire de l'immigration

\section{Édition imprimée}

Date de publication : 1 juillet 2015

Pagination : 1

ISBN : 978-2-919040-32-2

ISSN : $1142-852 X$

\section{Référence électronique}

Marie Poinsot, «Elles... leur combat pour la visibilité », Hommes \& migrations [En ligne], 1311 | 2015, mis en ligne le 23 février 2016, consulté le 23 septembre 2020. URL : http://journals.openedition.org/ hommesmigrations/3232; DOI : https://doi.org/10.4000/hommesmigrations.3232 


\section{ELLES.... LEUR COMBAT POUR LA VISIBILITÉ}

par MARIE POINSOT, rédactrice en chef.

Depuis cet été, l'actualité est marquée par les naufrages demilliers depersonnes quitentent de franchir lesfrontièreseuropéennespoursurvivre. Unnouveau défi migratoire s'impose à l'Europe. Parmi les figures dramatiques de ces aventures humaines, les familles syriennes interrogent de nouveau notre regard sur les représentations de l'immigration. En quoi les stéréotypes sur une immigration économique et majoritairement masculine sont-ils bousculés parces arrivées récentes?

Ce dossier est né d'un projet européen, Odyssée moderne, mené par le théâtre Dynamo à Marseille en relation avec des partenaires belges, roumains et turcs qui ont associé des collectes de récits de femmes migrantes, des ateliers d'écriture théâtrale et un cadrage par les sciences humaines. Il est parti d'un constat simple : les migrations féminines ont longtemps été l'angle mort de l'histoire de l'immigration et des débats contemporains. Dès lors, si la féminisation des flux migratoires s'affirme statistiquement depuis la fin des années 1990 dans les sociétés européennes, pourquoi observe-t-on un tel déficit de visibilité et de reconnaissance?

Pour y répondre, Hommes \& Migrations a voulu questionner cette visibilité des migrantes dans l'espace public, au sens large. Grâce à un trio de coordinateurs venus d'horizons géographiques et de disciplines complémentaires, sous la conduite experte de Mirjana Morokvasic, une figure pionnière dans les recherches croisant genre et migrations depuis trente ans, une quinzaine de travaux ont été identifiés. Ce dossier interroge tout d'abord les conditions de la "visibilisation" de cet objet de recherche dans l'agenda académique. Le thème des migrations féminines y émerge en même temps que le changement de paradigme qui domine les politiques migratoires menées jusqu'en 1974, date de la fermeture des migrations de travail dans les pays européens du Nord. L'invisibilité des femmes dépendait-elle pour autant d'une vision essentiellement masculine des migrations économiques? Certains articles montrent les conséquences durables, en terme de représentations, de l'inscription des femmes migrantes comme nouvelle catégorie de bénéficiaires des mesures sociales mises en place dans le cadre du regroupement familial.

Le changement de cap des politiques publiques va désormais assigner aux migrantes un rôle limité dans les dynamiques migratoires et une place en retrait dans les sociétés d'accueil. Par la suite, la figure des migrations féminines va permettre de réfléchir en terme de double discrimination (genre et origine) qui ouvre à son tour d'autres champs de recherche fructueux.

D'autres articles mettent l'accent sur les nouveaux profils des candidates à la mobilité internationale, souvent plus qualifiées que les générations précédentes et plus déterminées à s'affranchir de leur milieu familial et social en partant vivre ailleurs. Même au prix d'un déclassement professionnel initial. Si leur éducation et leurs diplômes ouvrent la voie aux visas, de manière systémique, les plus qualifiées des femmes parviennent difficilement aux positions sur le marché de travail auxquelles elles auraient droit. Il faut donc combiner plusieurs critères, dont ceux des compétences, du capital social et culturel, pour expliquer l'invisibilité actuelle des femmes dans les positions économiques les plus enviables où elles sont pourtant présentes grâce à leur énergie et à leur stratégie.

En 1991, la revue Hommes \& Migrations consacrait un panorama judicieusement intitulé "Elles... Femmes en mouvements" sur les réseaux associatifs des femmes selon leur origine géographique, toujours d'actualité. Les articles explorent à nouveau cette problématique pour souligner combien cet investissement des migrantes dans les associations et les actions citoyennes les aide à s'extraire des images qu'on leur accole. Elles s'expriment en donnant à voir d'autres facettes de leur réalité sociale et en privilégiant des formes de transmissions culturelles vers d'autres générations et vers la société d'accueil. Ainsi, les portraits de Dania, Jennie, Fatima, Marie, Maritza, Francine et d'autres femmes migrantes en région parisienne, réalisés par Sophie Pasquet, nous dévoilent des trajectoires professionnelles singulières qui sont autant de récits de soi dans la société française. 